Sains Malaysiana 49(1)(2020): 211-222

http://dx.doi.org/10.17576/jsm-2020-4901-25

\title{
Thermal Marangoni Flow Past a Permeable Stretching/Shrinking Sheet in a Hybrid $\mathrm{Cu}-\mathrm{Al}_{2} \mathrm{O}_{3} /$ Water Nanofluid \\ (Aliran Haba Marangoni terhadap Permukaan Telap Meregang/Mengecut dalam Nanobendalir Hibrid $\mathrm{Cu}-\mathrm{Al}_{2} \mathrm{O}_{3} / \mathrm{Air}$ )
}

\author{
Najiyah Safwa Khashi'Ie, Norihan Md Arifin*, IoAn Pop, Roslinda Nazar, \\ EZAD HAFIDZ HAFIDZUDDIN \& NADIHAH WAHI
}

\begin{abstract}
The present study accentuates the Marangoni convection flow and heat transfer characteristics of a hybrid $\mathrm{Cu}$ - $\mathrm{Al}_{2} \mathrm{O}_{3}$, water nanofluid past a stretching/shrinking sheet. The presence of surface tension due to an imposed temperature gradient at the wall surface induces the thermal Marangoni convection. A suitable transformation is employed to convert the boundary layer flow and energy equations into a nonlinear set of ordinary (similarity) differential equations. The bvp 4c solver in MATLAB software is utilized to solve the transformed system. The change in velocity and temperature, as well as the Nusselt number with the accretion of the dimensionless Marangoni, nanoparticles volume fraction and suction parameters, are discussed and manifested in the graph forms. The presence of two solutions for both stretching and shrinking flow cases are noticeable with the imposition of wall mass suction parameter. The adoption of stability analysis proves that the first solution is the real solution. Meanwhile, the heat transfer rate significantly augments with an upsurge of the $\mathrm{Cu}$ volume fraction (shrinking flow case) and Marangoni parameter (stretching flow case). Both Marangoni and $\mathrm{Cu}$ volume fraction parameters also can decelerate the boundary layer separation process.
\end{abstract}

Keywords: Dual solutions; hybrid nanofluid; Marangoni convection; stability analysis; suction

\section{ABSTRAK}

Kajian ini menonjolkan aliran perolakan Marangoni dan ciri-ciri pemindahan haba untuk nanobendalir hibrid Cu$\mathrm{Al}_{2} \mathrm{O}_{3}$ /air terhadap permukaan meregang/mengecut. Kehadiran ketegangan permukaan disebabkan oleh perbezaan suhu yang dikenakan pada permukaan dinding telah menghasilkan perolakan haba Marangoni. Satu transformasi bersesuaian digunakan untuk menukar persamaan aliran lapisan sempadan dan tenaga ke dalam persamaan pembezaan biasa bukan linear. Fungsi bvp4c dalam perisian Matlab telah digunakan untuk menyelesaikan sistem yang diubah. Perubahan dalam halaju dan suhu, serta nombor Nusselt dengan penambahan pemboleh ubah tanpa dimensi iaitu Marangoni, pecahan isi padu nanozarah dan sedutan, turut dibincangkan dan diwujudkan dalam bentuk graf. Kehadiran dua penyelesaian untuk kedua-dua kes aliran meregang dan mengecut dikenal pasti dengan penggunaan pemboleh ubah sedutan. Penggunaan analisis kestabilan telah mengesahkan yang penyelesaian pertama adalah penyelesaian sebenar. Pada masa yang sama, kadar pemindahan haba meningkat dengan banyak dengan penambahan pecahan isi padu Cu (kes aliran mengecut) dan pemboleh ubah Marangoni (kes aliran meregang). Kedua-dua pemboleh ubah Marangoni dan pecahan isi padu Cu juga dapat memperlahankan proses pemisahan aliran sempadan.

Kata kunci: Analisis kestabilan; nanobendalir hibrid; penyelesaian dwi; perolakan Marangoni; sedutan

\section{INTRODUCTION}

Energy sustainability and optimization of the thermal system efficiency has been the subject of developing research in most industrial and engineering sectors like power generation, microelectronics, and air conditioning. Ellahi et al. (2018) featured that an innovative diversity in thermodynamics was essential for the energy sustainability. The cooling systems which are incorporated in these engineering processes, work on a fluid medium through a forced flow with or without convective heat transfer (Jana et al. (2007). Therefore, it is worth to enhance the thermal conductivity of the fluid for better performance in the engineering process. The creation of nanofluid is developed by dispersing single nanoparticle into the regular liquids such as water, ethylene glycol, vegetable oil or the mixture of both water and ethylene glycol. The nanoparticles are classified into these groups; metal $(\mathrm{Cu}, \mathrm{Ag})$, metal oxides $\left(\mathrm{Al}_{2} \mathrm{O}_{3}, \mathrm{Fe}_{2} \mathrm{O}_{3}, \mathrm{CuO}\right)$, carbon materials (CNTs, MWCNTs), metal nitride and metal carbide. Rashidi et al. (2018) numerically showed that an upsurge of alumina $\left(\mathrm{Al}_{2} \mathrm{O}_{3}\right)$ solid volume fraction can increase the productivity of a single slope solar application. Akbarzadeh et al. (2018) investigated the simultaneous effects of $\mathrm{Cu}$ nanoparticles and wavy wall on the performance criterion evaluation (PEC), heat transfer and pressure drop of a solar heater application. The accretion of the $\mathrm{Cu}$ nanoparticles volume 
fraction (0 to 0.04$)$ increased the performance criterion evaluation (PEC) for all types of ducts (straight, sinusoidal and triangular). The $\mathrm{CuO}$-water nanofluid flow with convective heat transfer over a wavy surface in a porous medium was scrutinized by Hassan et al. (2018a). They also proved that the value of local Nusselt number enhanced with the addition of the nanoparticles volume fraction and consequently, improved the convective heat transfer from surface to the fluid. The recent investigations on the application of nanofluids were analyzed by Alamri et al. (2019), Amirsom et al. (2019), Aziz et al. (2018), Hassan et al. (2019), Khashi'ie et al. (2019), Mohamed et al. (2016), Sheikholeslami et al. (2019), Sohail et al. (2019), and Zaimi et al. (2017). However, there are also a few of literatures that highlighted the significance and application of nonNewtonian nanofluid in the fluid dynamics. Polymer melts, paints, biological solutions, tars and glues are among the non-Newtonian fluid which are widely used in the industrial and technological operations. The significant impact of the magnetic field and temperature dependent viscosity using non-Newtonian nanofluid inside a pipe was analyzed by Ellahi (2013) while Mahat et al. (2018) analyzed the mixed convective flow of viscoelastic nanofluid towards a circular cylinder with the consideration of viscous dissipation effect. Recently, the analysis on momentum and heat transfer of MHD Carreau nanofluid over a stretching plate was conducted by Yousif et al. (2019). They also considered both radiation and internal heat generation in their work.

The invention of a stable hybrid nanofluid as a promising heat transfer fluid with better heat transfer performance can fulfil the industrial demand. There are two ways to prepare hybrid nanofluids which is: by suspending different types of nanoparticles in a base fluid (water/oil) or by suspending hybrid form of nanoparticles in the base fluid. A clear review on hybrid nanofluids with recent development is reported by Sarkar et al. (2015). They discussed in detail the preparation methods of hybrid nanofluids by using three different base fluids (oil, water, and ethylene glycol). The review concluded that the proper technique of hybridization could make the hybrid nanofluids work efficiently for the heat transfer enhancement. A comprehensive analysis was prepared by Sidik et al. (2016), and it showed a similar conclusion. The thermal characteristics of hybrid nanofluid were higher as compared to the base fluid and fluid with single nanoparticles. Gupta et al. (2018) discussed the synthesis and thermophysical properties of the hybrid nanofluids. According to the study, types of nanoparticles, base fluid, substantial volume fraction, particle size and shape were among the elements that can affect thermophysical properties. Huminic and Huminic (2018) experimentally and numerically investigated the working hybrid nanofluids in the heat exchangers which resulted in that the heat transfer improved significantly.

However, there are still factors that need to be concerned such as various combinations of hybrid nanoparticles and the mixing ratio, which contributes to heat transfer intensification. A few studies regarding the thermophysical properties of the hybrid nanofluids were also conducted by these researchers (Ahmadi \& Willing 2018; Ahmadi et al. 2018; Akilu et al. 2016; Babu et al. 2017; Kamyar et al. 2012; Sundar et al. 2017). Different combinations of nanoparticles and base fluid were also considered, i.e. MgO-MWCNT/ethylene glycol by Soltani and Akbari (2016), MgO-MWCNTs/EG by Vafaei et al. (2017), $\mathrm{TiO}_{2}-\mathrm{Cu} / \mathrm{H}_{2} \mathrm{O}$ by Ghadikolaei et al. (2017), Ag-CuO/water by Hayat and Nadeem (2017) and Hayat et al. (2018), $\mathrm{Cu}-\mathrm{Ag} /$ water by Hassan et al. (2018b), Ag-MgO/water by Ghalambaz et al. (2019) and graphene-platinum hybrid nanofluids by Bahiraei and Mazaheri (2018), respectively. Devi and Devi (2016a) and Devi and Devi $(2017,2016 \mathrm{~b})$ investigated on the boundary layer flow of hybrid $\mathrm{Cu}-\mathrm{Al}_{2} \mathrm{O}_{3}$ /water nanofluid numerically due to a stretching sheet. Nadeem et al. (2018) explored the stagnation point flow of hybrid $\mathrm{Cu}-\mathrm{Al}_{2} \mathrm{O}_{3} /$ water nanofluid on a circular cylinder while Rostami et al. (2018) considered the combination of $\mathrm{SiO}_{2}$ and $\mathrm{Al}_{2} \mathrm{O}_{3}$ nanoparticles with water-based fluid to solve the mixed convective stagnation point flow on a porous flat plate. Most recently, Huminic and Huminic (2019) investigated on the effect of hybrid MgO-MWCNT/ethylene glycol nanofluid on the elliptical tube performance.

Marangoni convection is generated due to the variations of surface tension gradients, either in the temperature, concentration or both gradients. Marangoni convection is extensively applied in welding (Bachmann et al. 2016; Cui et al. 2018; Kidess et al. 2016), crystal growth (Minakuchi et al. 2017; Timoveef et al. 2015) and soap film stabilisation (Bournival et al. 2017; Raza et al. 2016). A brief explanation of the theory of Marangoni convection flow was discussed by Arifin et al. (2011). In the study, a similarity solution for the non-isobaric Marangoni boundary layer flow of single $\mathrm{Cu}, \mathrm{Al}_{2} \mathrm{O}_{3}$ and $\mathrm{TiO}_{2}$ nanoparticles in a water-based fluid was obtained, and it showed that nanoparticles with low thermal conductivity $\mathrm{TiO}_{2}$, have higher heat transfer rate. Arifin et al. (2013) examined the Marangoni flow of nanofluid over a flat surface and, Sastry et al. (2013) continued the problem by including the magnetic field effect. Hamid and Arifin (2014) extended both problems (Arifin et al. 2013; Sastry et al. 2013) by applying the wall mass suction and injection while Mat et al. (2013) imposed a thermal radiation parameter. Lin and Zheng (2015) observed the flow of copper-water nanofluid over a porous medium disk. Ellahi et al. (2016) and Lin et al. (2016) explored the particle shape effects on the Marangoni convection flow whereas Sheikholeslami and Ganji (2017) and Sheikholeslami and Chamkha (2017) examined the influence of Lorentz force. The impact of Marangoni convection on the boundary layer flow of carbon-water nanofluid was scrutinized by Hayat et al. (2017).

The enhancement of suction parameter with an adequate value in the boundary layer flow problem over shrinking sheet as discussed in earlier studies by Fang et al. (2010) and Miklavčič and Wang (2006) might induce two possible solutions. The first or physical solution is 
generally referred to the solution which converges first while the second solution shows different characteristics of natural fluid flow. Recently, the implementation of the stability analysis has been the subject of interest to validate the first solution as the real solution. Among the earlier studies on mathematical formulation of stability analysis were examined by Harris et al. (2009) Merkin (1986), Roşca and Pop (2013), and Weidman et al. (2006). Many recent works also discussed the existence of dual solutions and emphasis on stability analysis (Bakar et al. 2018; Dzulkifli et al. 2018; Hamid \& Nazar 2016; Jamaludin et al. 2018; Kamal et al. 2019; Naganthran et al. 2018; Soid et al. 2018). All the reported literatures implemented the bvp4c solver in the MATLAB software to examine the paired and stability solutions.

The preceding literatures discover that the investigation on boundary layer flow with the presence of Marangoni convection already have been conducted using nanofluid with single nanoparticles. However, to the best of our knowledge, there are no reported results on the Marangoni flow of a hybrid nanofluid towards a stretching/shrinking sheet. We also consider the shrinking flow since boundary layer separation (laminar to turbulent) mostly occur during this flow. Meanwhile, the application of hybrid nanofluid in the boundary layer flow is also a new knowledge and still have not been explored by many researchers. Therefore, in the present work, the stretched/shrinked flow of a hybrid $\mathrm{Cu}-\mathrm{Al}_{2} \mathrm{O}_{3} /$ water nanofluid towards a permeable surface with Marangoni convection is scrutinized. Following the hybrid nanofluid model proposed by Devi and Devi (2016a), the Marangoni flow coupled with the energy equations are constructed. A similarity transformation is employed to convert the PDEs into a system of ODEs. The bvp4c function in MATLAB software is used to perform the numerical computations. The similarity solutions are graphically demonstrated for the velocity and temperature, including the Nusselt number within the specific range of related parameters. The present work is also concerned about the existence of non-unique solutions and the way of stability analysis is conducted to mathematically prove the physical solution.

\section{MATHEMATICAL FORMULATION}

Consider the steady thermal Marangoni convection flow of a nanoliquid comprising of hybrid nanoparticles past a permeable stretching/shrinking sheet. The flow is steady, two-dimensional and incompressible. Surface temperature gradient developing surface tension is main agent for flow induction, as illustrated in Figure 1, where $x$ and $y$ are the Cartesian coordinates measured parallel and normal to the stretching/shrinking surface. The reference velocity of the stretching/shrinking sheet is $u_{w}(x)=a x$ where $a>0$. The temperature of the sheet is considered as $T_{w}(x)=T_{\infty}+T_{0}(x / L)^{2}$ while that of the ambient fluid is $T_{\infty}$ where $T_{0}$ is the characteristic temperature and $L$ is the characteristic length of the sheet.
Under these assumptions, the basic equations of the problem under consideration are (Devi \&Devi (2016a)):

$$
\begin{aligned}
& \frac{\partial u}{\partial x}+\frac{\partial v}{\partial y}=0, \\
& u \frac{\partial u}{\partial x}+v \frac{\partial u}{\partial y}=\frac{\mu_{h n f}}{\rho_{h n f}} \frac{\partial^{2} u}{\partial y^{2}}, \\
& u \frac{\partial T}{\partial x}+v \frac{\partial T}{\partial y}=\frac{k_{h n f}}{\left(\rho C_{p}\right)_{h n f}} \frac{\partial^{2} T}{\partial y^{2}} .
\end{aligned}
$$

The surface tension $(\sigma)$ is taken to be linear function of temperature i.e.

$$
\left.\left.\sigma=\sigma_{0}\left[1-\gamma_{T}\left(T-T_{\infty}\right)\right] \text { where } \gamma_{T}=-\frac{1}{\sigma_{0}} \frac{\partial \sigma}{\partial T}\right)_{T=T_{\infty}}\right\}
$$

where $\gamma_{T}$ designates coefficient of temperature surface tension and $\sigma_{0}>0$. The relevant initial and boundary conditions of (1) to (3) are

$$
\begin{aligned}
& v=v_{0},\left.\mu_{h r f} \frac{\partial u}{\partial y}\right|_{y=0}=\left.\lambda \frac{\partial \sigma}{\partial y}\right|_{y=0}=\left.\lambda \frac{\partial \sigma}{\partial T} \frac{\partial T}{\partial x}\right|_{y=0}, T=T_{w}(x) \text { at } y=0 \\
& u \rightarrow 0, T \rightarrow T_{\infty} \text { as } y \rightarrow \infty
\end{aligned}
$$

Here $u$ and $v$ are the velocity components of the hybrid nanofluid along $x$ - and $y$ - axes, $T$ is the temperature of the hybrid nanofluid, $v_{0}$ is the constant mass flux velocity with $v_{0}<0$ for injection, $v_{0}<0$ for suction and $\lambda$ is the constant stretching/shrinking parameter with $\lambda$ $<0$ is for shrinking sheet and $\lambda<0$ for stretching sheet, correspondingly. Further, $\mu_{h n f}$ is the dynamic viscosity of the hybrid nanofluids, $\rho_{h n f}$ is the density of the hybrid nanofluids, $k_{h n f}$ is the thermal conductivity of the hybrid

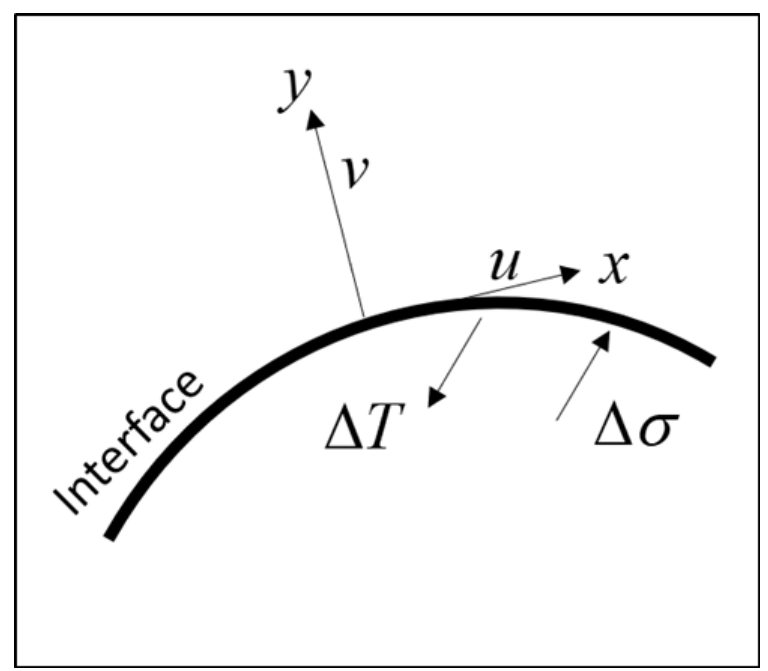

FIGURE 1. An illustration of the physical model 
TABLE 1. Physical properties of nanofluid and hybrid nanofluid (Devi \& Devi (2016a) and Devi and Devi (2017, 2016b)

\begin{tabular}{|c|c|c|}
\hline Properties & Nanofluid & Hybrid nanofluid \\
\hline Density & $\rho_{n f}=(1-\phi) \rho_{f}+\phi \rho_{s}$ & $\rho_{h n f}=\left(1-\phi_{2}\right)\left[\begin{array}{l}\left(1-\phi_{1}\right) \rho_{f} \\
+\phi_{1} \rho_{s 1}\end{array}\right]+\phi_{2} \rho_{s 2}$ \\
\hline Heat capacity & $\begin{aligned}\left(\rho C_{p}\right)_{n f}= & (1-\phi)\left(\rho c_{p}\right)_{f} \\
& +\phi\left(\rho c_{p}\right)_{s}\end{aligned}$ & $\begin{aligned}\left(\rho C_{p}\right)_{h n f}= & \left(1-\phi_{2}\right)\left[\begin{array}{l}\left(1-\phi_{1}\right)\left(\rho c_{p}\right)_{f} \\
+\phi_{1}\left(\rho c_{p}\right)_{s 1}\end{array}\right] \\
& +\phi_{2}\left(\rho c_{p}\right)_{s 2}\end{aligned}$ \\
\hline Dynamic viscocity & $\frac{\mu_{n f}}{\mu_{f}}=\frac{1}{\left(1-\phi_{1}\right)^{2.5}}$ & $\frac{\mu_{h n f}}{\mu_{f}}=\frac{1}{\left(1-\phi_{1}\right)^{2.5}\left(1-\phi_{2}\right)^{2.5}}$ \\
\hline Thermal conductivity & $\frac{k_{n f}}{k_{f}}=\left[\frac{k_{s}+2 k_{f}-2 \phi\left(k_{f}-k_{s}\right)}{k_{s}+2 k_{f}+\phi\left(k_{f}-k_{s}\right)}\right]$ & $\begin{array}{l}\frac{k_{h n f}}{k_{b f}}=\left[\frac{k_{s 2}+2 k_{b f}-2 \phi_{2}\left(k_{b f}-k_{s 2}\right)}{k_{s 2}+2 k_{b f}+\phi_{2}\left(k_{b f}-k_{s 2}\right)}\right] \\
\text { where } \\
\frac{k_{b f}}{k_{f}}=\left[\frac{k_{s 1}+2 k_{f}-2 \phi_{1}\left(k_{f}-k_{s 1}\right)}{k_{s 1}+2 k_{f}+\phi_{1}\left(k_{f}-k_{s 1}\right)}\right]\end{array}$ \\
\hline
\end{tabular}

TABLE 2. Thermo physical properties (Khanafer et al. (2003) and Oztop and Abu-Nada (2007))

\begin{tabular}{lccc}
\hline Physical properties & Water & $\mathrm{Al}_{2} \mathrm{O}_{3}$ & $\mathrm{Cu}$ \\
\hline$\rho\left(\mathrm{kg} / \mathrm{m}^{3}\right)$ & 997.1 & 3970 & 8933 \\
$C_{p}(\mathrm{~J} / \mathrm{kgK})$ & 4179 & 765 & 385 \\
$k(W / m K)$ & 0.6130 & 40 & 400 \\
\hline
\end{tabular}

nanofluid and $\left(\rho C_{p}\right)_{h n f}$ is the heat capacity of the hybrid nanofluid. Physical properties of nanofluids and hybrid nanofluids are given in Table 1.

Further, $\rho_{f}$ and $\rho_{s}$ are the densities of the base fluid and the hybrid nanoparticle, correspondingly, $C_{p}$ is the heat capacity at the constant pressure, $\phi$ is the nanoparticle volume fraction, $k_{f}$ and $k_{s}$ are the thermal conductivities of the base fluid and the hybrid nanoparticles, respectively, and $\left(\rho C_{p}\right)_{f}$ and $\left(\rho C_{p}\right)_{s}$ are the heat capacitance of the base fluid and the hybrid nanoparticle, respectively. The physical properties of the base fluid (water), alumina $\left(\mathrm{Al}_{2} \mathrm{O}_{3}\right.$ and copper $(\mathrm{Cu})$ hybrid nanofluids are given in Table 2 .

According to Devi and Devi(2016a), we are looking for a similarity solution of (1) to (3) along with boundary conditions (5) of the following form:

$$
u=a x f^{\prime}(\eta), v=-\sqrt{a v_{f}} f(\eta), \theta(\eta)=\frac{T-T_{\infty}}{T_{w}-T_{\infty}}, \eta=y / \sqrt{v_{f} / a},
$$

where primes denote differentiation with respect to . Thus, we have

$$
v_{0}=-\sqrt{a v_{f}} S
$$

where $S$ is the constant mass flux velocity with $S<0$ for injection and $S>0$ for suction, respectively. Substituting (6) into (2) and (3), we obtain the following ordinary (similarity) differential equations,

$$
\begin{aligned}
& \frac{\mu_{h r f} / \mu_{f}}{\rho_{h r f} / \rho_{f}} f^{\prime \prime \prime}+f f^{\prime \prime}-f^{\prime 2}=0 \\
& \frac{1}{\operatorname{Pr}} \frac{k_{h r f} / k_{f}}{\left(\rho C_{p}\right)_{h r f} /\left(\rho C_{p}\right)_{f}} \theta^{\prime \prime}+f \theta^{\prime}-2 f^{\prime} \theta=0
\end{aligned}
$$

and the transformed conditions are

$$
\begin{aligned}
& f(0)=S, \quad f^{\prime \prime}(0)=-2 \operatorname{Ma\lambda }\left(1-\phi_{1}\right)^{2.5}\left(1-\phi_{2}\right)^{2.5}, \quad \theta(0)=1, \\
& f^{\prime}(\eta) \rightarrow 0, \quad \theta(\eta) \rightarrow 0,
\end{aligned}
$$

Here $\operatorname{Pr}=\frac{\left(C_{p} \mu\right)_{f}}{k_{f}}$ is the Prandtl number and $M a=\frac{\sigma_{0} \gamma_{T} T_{0}}{L^{2} a \sqrt{a \rho_{f} \mu_{f}}}$ is the Marangoni parameter. The quantity of physical interest is the local Nusselt number, which is defined as

$$
N u_{x}=\frac{x q_{w}}{k_{f}\left(T_{w}-T_{\infty}\right)},
$$


and

$$
q_{w}=-k_{h n f}\left(\frac{\partial T}{\partial y}\right)_{y=0} .
$$

$$
\left.\begin{array}{l}
f(\eta, \tau)=f_{0}(\eta)+e^{-\gamma \tau} F(\eta), \\
\theta(\eta, \tau)=\theta_{0}(\eta)+e^{-\gamma \tau} G(\eta),
\end{array}\right\}
$$

Using (6), (11) and (12), we get

$$
\mathrm{Re}_{x}^{-1 / 2} N u_{x}=\frac{k_{h n f}}{k_{f}}\left[-\theta^{\prime}(0)\right],
$$

where $R e_{x}=u_{w}(x) x / v_{f}$ is the local Reynolds number.

\section{STABILITY ANALYSIS}

Stability analysis is carried out if the (similarity) differential equations in (8)-(10) possess dual or multiple solutions. It is important for a mathematician to find all the possible solutions (unique/non-unique) arise from the governing boundary layer problem and thus, validate the real solution. Following previous literatures, first step in the stability analysis is to consider a new time-based transformation which is,

$$
u=a x \frac{\partial f(\eta, \tau)}{\partial \eta}, v=-\sqrt{a v_{f}} f(\eta, \tau), \theta(\eta, \tau)=\frac{T-T_{\infty}}{T_{w}(x)-T_{\infty}}, \eta=\sqrt{\frac{a}{v_{f}}} y, \quad \tau=a t,
$$

where $\tau$ is the dimensionless time variable to the unsteady form of (2)-(6) such that

$$
\begin{aligned}
& \frac{\partial u}{\partial t}+u \frac{\partial u}{\partial x}+v \frac{\partial u}{\partial y}=\frac{\mu_{h n f}}{\rho_{h n f}} \frac{\partial^{2} u}{\partial y^{2}}, \\
& \frac{\partial T}{\partial t}+u \frac{\partial T}{\partial x}+v \frac{\partial T}{\partial y}=\frac{k_{h n f}}{\left(\rho C_{p}\right)_{h n f}} \frac{\partial^{2} T}{\partial y^{2}} .
\end{aligned}
$$

The new nonlinear differential equations are attained

$$
\begin{aligned}
& \frac{\mu_{h n f} / \mu_{f}}{\rho_{h r f} / \rho_{f}} \frac{\partial^{3} f}{\partial \eta^{3}}+f \frac{\partial^{2} f}{\partial \eta^{2}}-\left(\frac{\partial f}{\partial \eta}\right)^{2}-\frac{\partial^{2} f}{\partial \eta \partial \tau}=0, \\
& \frac{1}{\operatorname{Pr}} \frac{k_{h n f} / k_{f}}{\left(\rho C_{p}\right)_{h r f} /\left(\rho C_{p}\right)_{f}} \frac{\partial^{2} \theta}{\partial \eta^{2}}+f \frac{\partial \theta}{\partial \eta}-2 \theta \frac{\partial f}{\partial \eta}-\frac{\partial \theta}{\partial \tau}=0,
\end{aligned}
$$

along with the initial and boundary conditions

$$
\left.\begin{array}{l}
f(0, \tau)=S, \quad \frac{\partial^{2} f}{\partial \eta^{2}}(0, \tau)=-2 \operatorname{Ma}\left(1-\phi_{1}\right)^{2.5}\left(1-\phi_{2}\right)^{2.5}, \quad \theta(0, \tau)=1, \\
\frac{\partial f}{\partial \eta}(\infty, \tau) \rightarrow 0, \quad \theta(\infty, \tau) \rightarrow 0,
\end{array}\right\}
$$

Further, the expressions in (20) are proposed to test the reliability of the steady flow solutions $f(\eta)=f_{0}(\eta)$ and $\theta$ $(\eta)=\theta_{0}(\eta)$ by incorporating with an eigenvalue $\gamma, F(\eta)$ and $G(\eta)$. It is worth mentioning that $F(\eta)$ and $G(\eta)$ are small relative to $f_{0}(\eta)$ and $\theta_{0}(\eta)$, accordingly.
The following linearized eigenvalue problem is obtained by substituting (20) into (17)-(19),

$$
\begin{aligned}
& \frac{\mu_{h r f} / \mu_{f}}{\rho_{h n f} / \rho_{f}} F^{\prime \prime \prime}+F f_{0}^{\prime \prime}+f_{0} F^{\prime \prime}-\left(2 f_{0}^{\prime}-\gamma\right) F^{\prime}=0, \\
& \frac{1}{\operatorname{Pr}} \frac{k_{h r f} / k_{f}}{\left(\rho C_{p}\right)_{h r f} /\left(\rho C_{p}\right)_{f}} G^{\prime \prime}+F \theta_{0}^{\prime}+f_{0} G^{\prime}-2 F^{\prime} \theta_{0}-\left(2 f_{0}^{\prime}-\gamma\right) G=0,
\end{aligned}
$$

inclusive of the conditions

$$
\left.\begin{array}{l}
F(0)=F^{\prime \prime}(0)=G(0)=0, \\
F^{\prime}(\infty) \rightarrow 0, \quad G(\infty) \rightarrow 0,
\end{array}\right\}
$$

Relaxation of a boundary condition $F^{\prime}(\infty) \rightarrow 0$ or $G^{\prime}(\infty)$ $\rightarrow 0$ is needed to generate a possible range of eigenvalues (Harris et al. 2009). The smallest eigenvalue denoted by $\gamma_{1}$ acts as a determinant of the stability solution. In the present problem, $F^{\prime}(\infty) \rightarrow 0$ in $(23)$ is rested and swapped with a new boundary condition $F^{\prime}(0)=1$.

\section{NUMERICAL PROCEDURE}

The resulting nonlinear ordinary (similarity) differential equations (ODEs) in (8) and (9) together with the boundary conditions (10) are numerically solved using the bvp4c solver in the MATLAB software. The bvp4c (boundary value problem with fourth order accuracy) solver was introduced by Shampine et al. (2003) and programmed with a finite difference scheme known as 3-stage Lobatto IIIa. Using this solver, the users are required to provide a set of initial guesses with the combination of suitable boundary layer thickness $\eta_{\infty}$ The correct results are obtained within the specified accuracy when the farfield boundary conditions (10) are asymptotically satisfied and no error generated from the MATLAB software. Further, the users need to give a few of trial and error in supplying the initial guesses until the required results are obtained. There are few of literatures that discussed the bvp4c procedure in solving steady flow problem (Waini et al. 2019; Yahaya et al. 2018). Generally, the basic syntax in the bvp4c solver is sol=bvp4c (@OdeBVP, @OdeBC, solinit, options). To solve (8) and (9) inclusive with the conditions (10), it is necessary to reduce these equations as follows:

$$
\begin{aligned}
& f=y(1), \\
& f^{\prime}=y(2), \\
& f^{\prime \prime}=y(3),
\end{aligned}
$$




$$
\begin{aligned}
f^{\prime \prime \prime} & =\frac{\rho_{h n f} / \rho_{f}}{\mu_{h n f} / \mu_{f}}\left(f^{\prime 2}-f f^{\prime \prime}\right) \\
& =\frac{\rho_{h n f} / \rho_{f}}{\mu_{h n f} / \mu_{f}}(y(2) y(2)-y(1) y(3)), \\
\theta & =y(4), \\
\theta^{\prime} & =y(5), \\
\theta^{\prime \prime} & =\operatorname{Pr} \frac{\left(\rho C_{p}\right)_{h n f} /\left(\rho C_{p}\right)_{f}}{k_{h n f} / k_{f}}\left(2 f^{\prime} \theta-f \theta^{\prime}\right) \\
& =\operatorname{Pr} \frac{\left(\rho C_{p}\right)_{h n f} /\left(\rho C_{p}\right)_{f}}{k_{h n f} / k_{f}}(2 y(2) y(4)-y(1) y(5)),
\end{aligned}
$$

and

$$
\begin{aligned}
& f(0)-S=0, \quad f^{\prime \prime}(0)+2 \operatorname{Ma} \lambda\left(1-\phi_{1}\right)^{2.5}\left(1-\phi_{2}\right)^{2.5}=0, \quad \theta(0)-1=0, \\
& f^{\prime}(\eta) \rightarrow 0, \quad \theta(\eta) \rightarrow 0, \\
& y a(1)-S, \quad y a(3)+2 \operatorname{Ma} \lambda\left(1-\phi_{1}\right)^{2.5}\left(1-\phi_{2}\right)^{2.5}, \quad y a(4)-1 \\
& y b(2), \quad y b(4)
\end{aligned}
$$

Equations (24) and (25) are coded into the function @OdeBVP while (26) is coded in @OdeBC. Meanwhile, the function solinit contains the point of initial mesh and initial guesses at the mesh points. Two or multiple solutions are obtained if there is another initial guesses in the solinit that also fulfill the farfield boundary conditions (10). In the bvp4c solver, four separate codes are used; code a for solving the steady flow problem, code $b$ for the continuation of code $\mathrm{a}$, code $\mathrm{c}$ and $\mathrm{d}$ for the stability of the first and second solutions, respectively. Using code $\mathrm{c}$ and $\mathrm{d}$, the authors manage to find the smallest eigenvalue for both solutions. The linearized eigenvalue problem (21) and (22) with the boundary conditions (23) are rewritten in the form of,

$$
\begin{aligned}
& F=y(1), \quad f_{0}=s(1), \\
& F^{\prime}=y(2), \quad f_{0}^{\prime}=s(2), \\
& F^{\prime \prime}=y(3), \quad f_{0}^{\prime \prime}=s(3), \\
& G=y(4), \quad \theta_{0}=s(4), \\
& G^{\prime}=y(5), \quad \theta_{0}^{\prime}=s(5), \\
& F^{\prime \prime \prime}=\frac{\rho_{h n f} / \rho_{f}}{\mu_{h n f} / \mu_{f}}\left[\left(2 f_{0}^{\prime}-\gamma\right) F^{\prime}-F f_{0}^{\prime \prime}-f_{0} F^{\prime \prime}\right] \\
&=\frac{\rho_{h n f} / \rho_{f}}{\mu_{h n f} / \mu_{f}}[(2 s(2)-\gamma) y(2)-y(1) s(3)-s(1) y(3)] \\
& G^{\prime \prime}=\operatorname{Pr} \frac{\left(\rho C_{p}\right)_{h n f} /\left(\rho C_{p}\right)_{f}}{k_{h n f} / k_{f}}\left[2 F^{\prime} \theta_{0}+\left(2 f_{0}^{\prime}-\gamma\right) G-F \theta_{0}^{\prime}-f_{0} G^{\prime}\right] \\
&=\operatorname{Pr} \frac{\left(\rho C_{p}\right)_{h n f} /\left(\rho C_{p}\right)_{f}}{k_{h r f} / k_{f}}[2 y(2) s(4)+(2 s(2)-\gamma) y(4)-y(1) s(5)-s(1) y(5)]
\end{aligned}
$$

$$
\begin{aligned}
& y a(1), \quad y a(2)-1, \quad y a(3), \quad y a(4) \\
& y b(4)
\end{aligned}
$$

\section{RESUlTS AND DisCUSSION}

The utilization of bvp $4 \mathrm{c}$ codes to solve both steady flow and normalizing stability equations are successfully computed and validated by the previous studies. In the present work, $\eta_{\infty}=15$ is used to perform the computations but it is observed that $\eta_{\infty}=10$ is tolerable to fulfil the boundary conditions in (10) as displayed in Figures 4 to 9. Table 3 compares the values of $f^{\prime \prime}(0)$ and $\theta^{\prime}(0)$ with the earlier published results to validate the method (bvp $4 \mathrm{c}$ code) used in the present study. The present results were found to be in favourable agreement with Hamid and Arifin (2014) and Sastry et al. (2013).

According to Devi and Devi (2017, 2016a, 2016b) and Nadeem et al. (2018), the preparation of a hybrid $\mathrm{Cu}-\mathrm{Al}_{2} \mathrm{O}_{3}$ /water nanofluid was initially started by adding the alumina $\left(\mathrm{Al}_{2} \mathrm{O}_{3}\right)$ nanoparticles into the base fluid (water) and consequently, copper $(\mathrm{Cu})$ was combined with the mixture $\left(\mathrm{Al}_{2} \mathrm{O}_{3}\right.$-water nanofluid) with different solid volume fractions to form a hybrid nanofluid, namely $\mathrm{Cu}-\mathrm{Al}_{2} \mathrm{O}_{3} /$ water. Following their works, the nanoparticle volume fraction for $\mathrm{Al}_{2} \mathrm{O}_{3}\left(\phi_{1}\right)$ was kept as constant at $\phi_{1}$ $=0.1$ in the entire study whereas the range of $0.05 \leq \phi_{2} \leq$ 0.09 was considered for copper $(\mathrm{Cu}) . \operatorname{Pr}=6.2$ was used to symbolize water as the working fluid. The invention of stable nanofluids was to optimize the thermal properties with the least usage of nanoparticles in the working fluids (Arifin et al. 2011). It was also worth to mention that the combination of water-based fluid and both nanoparticles $\phi_{1}=0.1, \phi_{2}=[0.05,0.09]$ will create a $\mathrm{Cu}-\mathrm{Al}_{2} \mathrm{O}_{3} /$ water hybrid nanofluid whereas the dispersion of single nanoparticle such that $\phi_{1}=0, \phi_{2}=[0.05,0.09]$ or $\phi_{1}=0.1$, $\phi_{2}=0$ will produce $\mathrm{Cu}$-water and $\mathrm{Al}_{2} \mathrm{O}_{3}$-water nanofluids, respectively. On the other hand, the present analysis reduces to the viscous (Newtonian) fluid when $\phi_{1}=\phi_{2}=0$.

Figure 2 exhibits the heat transfer rate, $\operatorname{Re}_{x}^{-1 / 2} N u_{x}$ of $\mathrm{Cu}-\mathrm{Al}_{2} \mathrm{O}_{3} /$ water hybrid nanofluid towards $\lambda$ for different values of $\phi_{2}$. First and second solutions exist in the range of $\lambda_{\mathrm{c}}<\lambda \leq 1$ while no solution was noticed for $\lambda<\lambda_{\mathrm{c}}$ where $\lambda_{\mathrm{c}}$ is the critical value of the stretching/shrinking parameter. This critical value is important because at this point, the boundary layer starts separating from laminar to turbulent and most of the separation process occurs during the shrinking flow. In addition, the existence of dual solutions is related to the imposition of wall mass suction. Enough value of suction parameter, such as $S>2$ will induce two solutions (Bakar et al. 2018; Fang et al. 2010; Miklavčič \& Wang 2006). A critical/separating value is characterized as a meet point of both first and second solutions where a distinctive or unique solution was obtained at $\lambda=\lambda_{\mathrm{c}}$ It is apparent that $\mathrm{Cu}-\mathrm{Al}_{2} \mathrm{O}_{3}$ /water hybrid nanofluid with $\phi_{2}=0.09$ has larger value of $\left|\lambda_{c}\right|$ which can delay the boundary layer separation process. It is noted that for 
TABLE 3. Comparison values of $f^{\prime \prime}(0)$ and $\theta^{\prime}(0)$ for $\mathrm{Cu}$-water with $\lambda=1, M a=1$ and $S=0$

\begin{tabular}{lcccccc}
\hline & \multicolumn{2}{c}{ Present } & \multicolumn{2}{c}{ Sastry et al. (2013) } & \multicolumn{2}{c}{ Hamid and Arifin (2014) } \\
& $f^{\prime \prime}(0)$ & $\theta^{\prime}(0)$ & $f^{\prime \prime}(0)$ & $\theta^{\prime}(0)$ & $f^{\prime \prime}(0)$ & $\theta^{\prime}(0)$ \\
\hline 0.1 & -1.53687 & -3.40694 & -1.53687 & -3.40361 & -1.53687 & -3.40259 \\
0.2 & -1.14487 & -2.58874 & -1.14487 & -2.58644 & -1.14487 & -2.58469 \\
\hline
\end{tabular}

TABLE 4. Smallest eigenvalue $\gamma_{1}$ at several values of $\lambda$ when $\phi_{2}=0.09, M a=1$ and $S=0$

\begin{tabular}{lcc}
\hline$\lambda$ & & $\gamma_{1}$ \\
\hline-3.4 & First solution & Second solution \\
-3.49 & 0.4939 & -0.4768 \\
-3.4961 & 0.1279 & -0.1268 \\
-3.4963 & 0.0329 & -0.0329 \\
-3.4965 & 0.0242 & -0.0242 \\
\hline
\end{tabular}

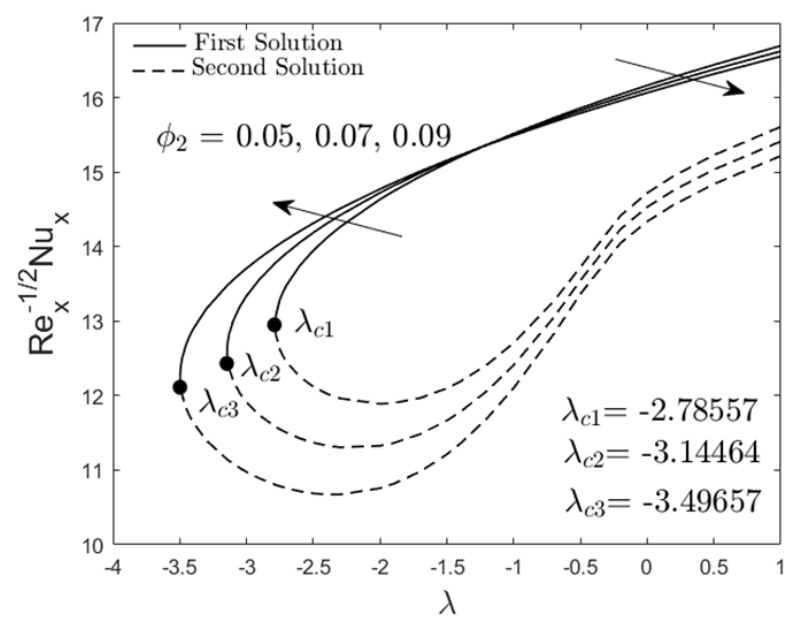

FIGURE 2. Heat transfer rate of $\mathrm{Cu}-\mathrm{Al}_{2} \mathrm{O}_{3}$ /water hybrid nanofluids towards $\lambda$ for various $\phi_{2}$ with $M a=1$ and $S=2.7$ and $\operatorname{Pr}=6.2$

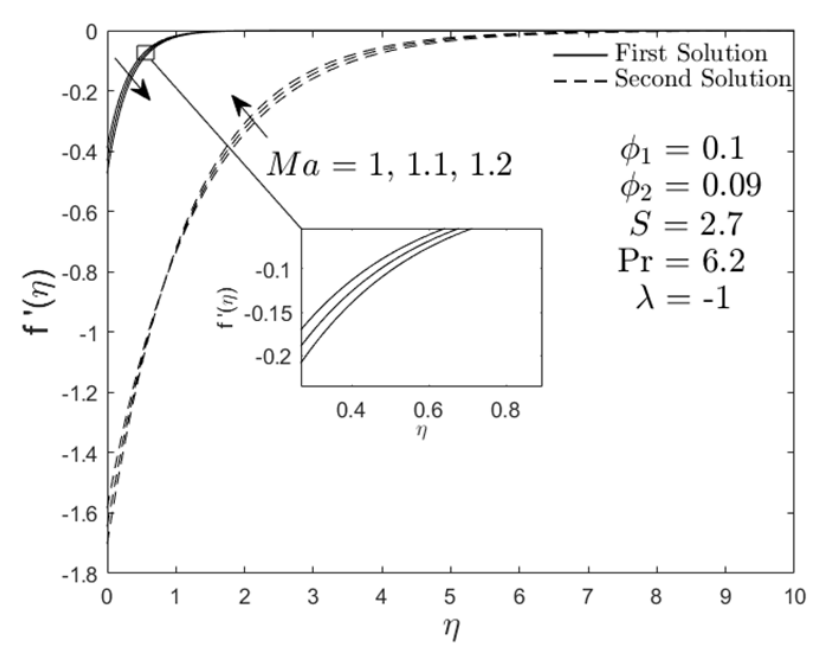

FIGURE 4. Effect of Marangoni parameter $\mathrm{Ma}$ on $\mathrm{Cu}-\mathrm{Al}_{2} \mathrm{O}_{3} /$ water hybrid nanofluid velocity

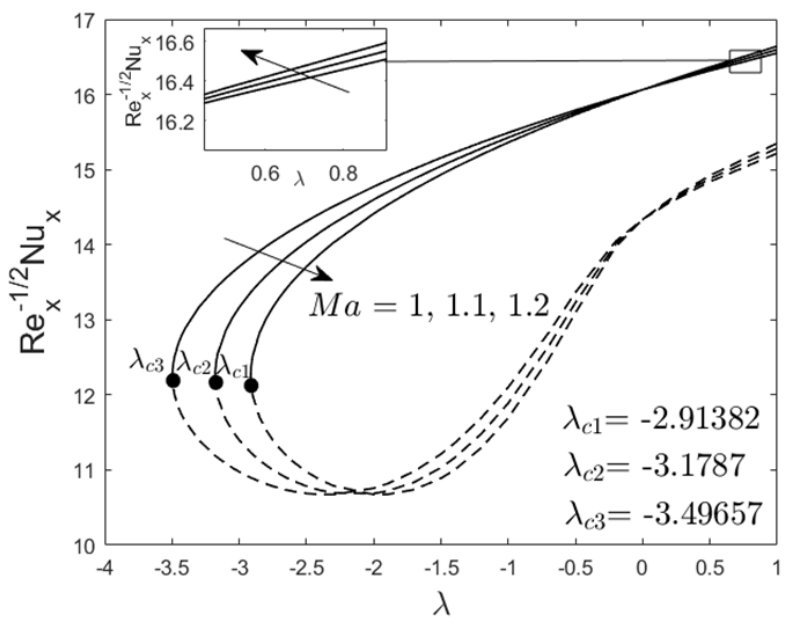

FIGURE 3. Heat transfer rate of $\mathrm{Cu}-\mathrm{Al}_{2} \mathrm{O}_{3}$ /water hybrid nanofluids towards $\lambda$ for various $M a$ with $\phi_{2}=0.09$ and $S=2.7$ and $\operatorname{Pr}=6.2$

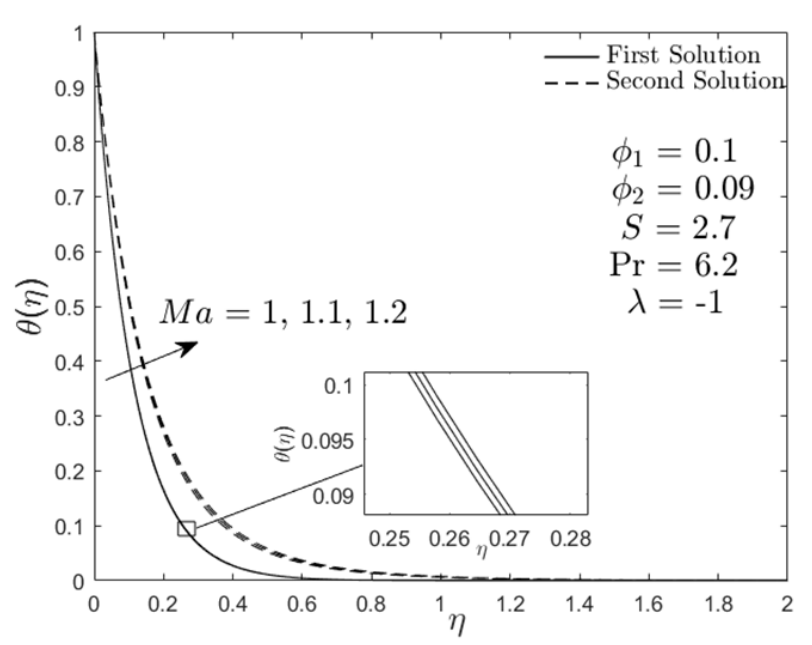

FIGURE 5. Effect of Marangoni parameter $\mathrm{Ma}$ on $\mathrm{Cu}-\mathrm{Al}_{2} \mathrm{O}_{3} /$ water hybrid nanofluid temperature 


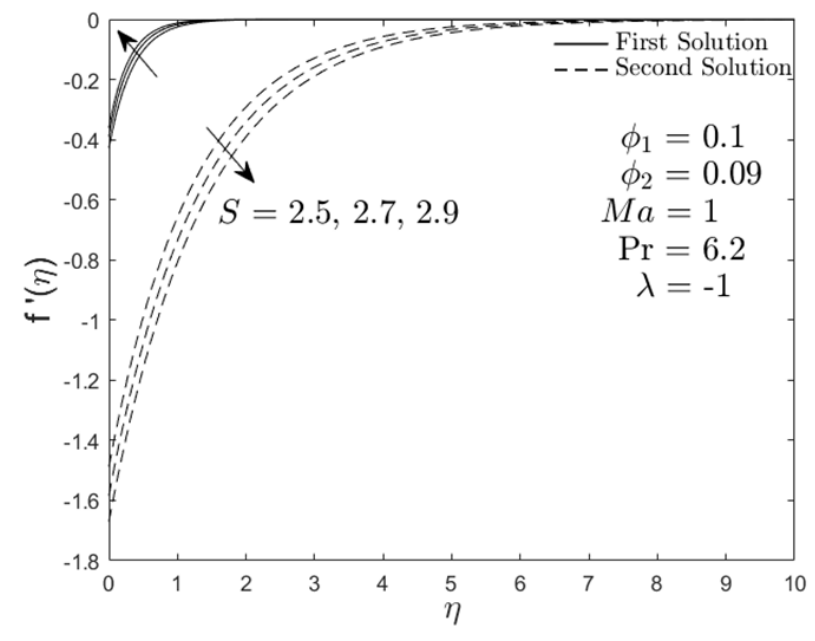

FIGURE 6. Effect of suction parameter $S$ on $\mathrm{Cu}-\mathrm{Al}_{2} \mathrm{O}_{3}$ /water hybrid nanofluid velocity

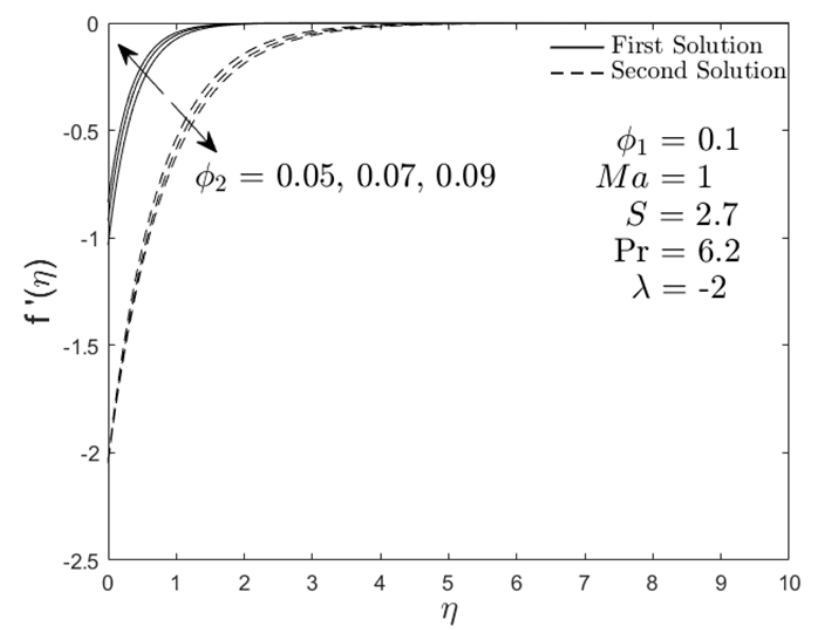

FIGURE 8. Effect of $\phi_{2}$ on $\mathrm{Cu}-\mathrm{Al}_{2} \mathrm{O}_{3}$ /water hybrid nanofluid velocity

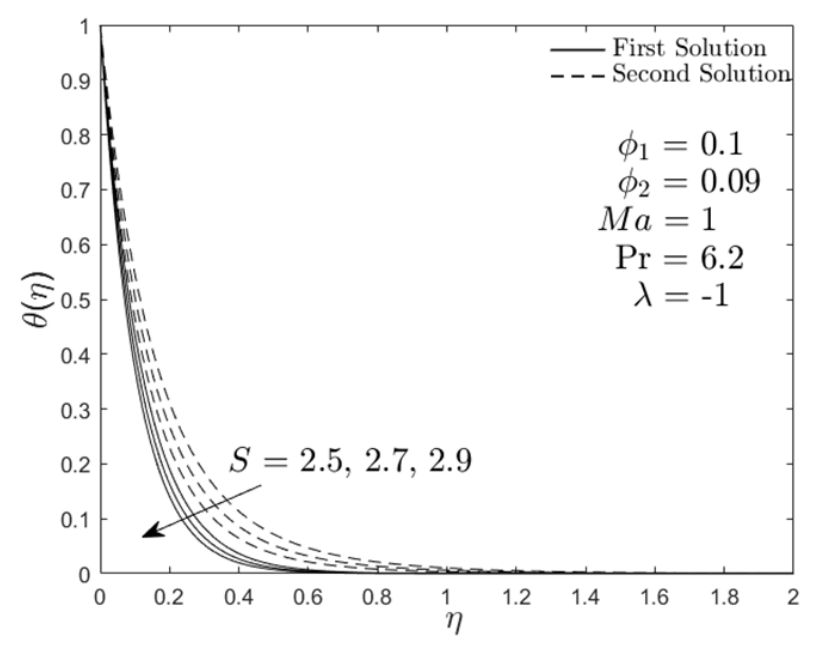

FIGURE 7. Effect of suction parameter $S$ on $\mathrm{Cu}-\mathrm{Al}_{2} \mathrm{O}_{3} /$ water hybrid nanofluid temperature

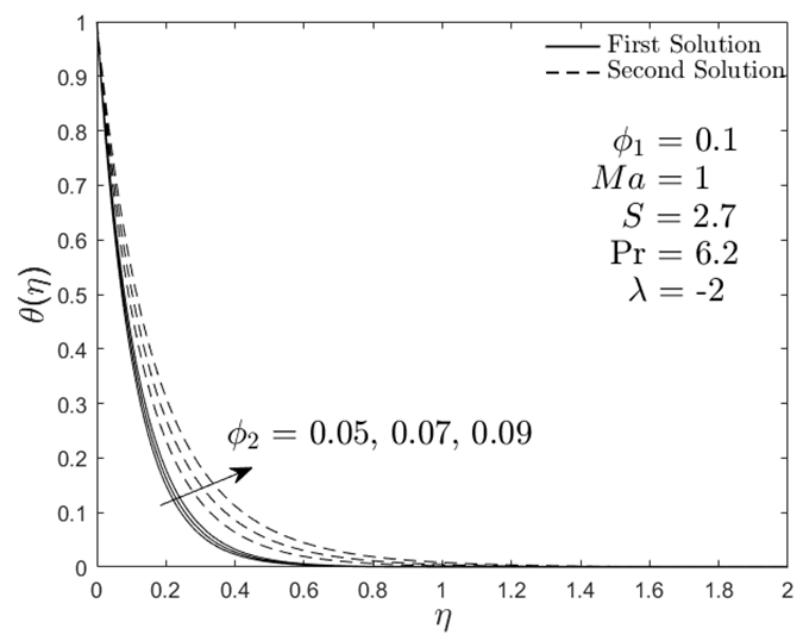

FIGURE 9. Effect of $\phi$, on Cu-A12O3/water hybrid nanofluid temperature

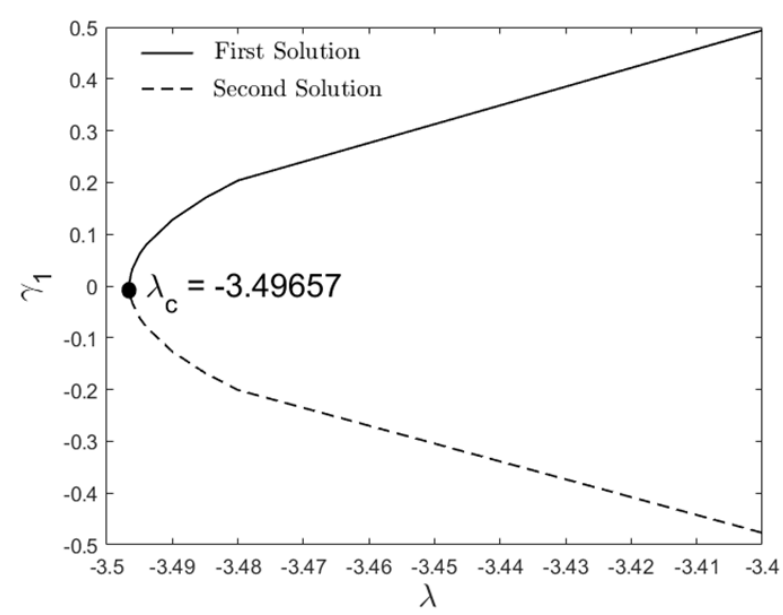

FIGURE 10. The smallest eigenvalue $\gamma_{1}$ of first and second solutions towards $\lambda$ 
$\lambda<\lambda_{\text {c }}$ boundary layer separation occurs and full NavierStokes with energy equations are used to observe the flow and heat transfer characteristics. An interesting outcome is also observed, where the thermal Marangoni flow of $\mathrm{Cu}-\mathrm{Al}_{2} \mathrm{O}_{3} /$ water hybrid nanofluid with $\phi_{2}=0.09$ has the optimum value of heat transfer rate as $\lambda \rightarrow-\lambda_{\mathrm{c}}$ (shrinking surface), while the opposite result is obtained when $\lambda \rightarrow$ $+\lambda_{\mathrm{c}}$ (stretching surface). The positive values of $\mathrm{Re}_{x}^{-1 / 2}$ $N u_{x}$ indicates that the heat transfer process is from the hot interface to the cold region (Arifin et al. 2011). Therefore, in the real engineering processes, one of the approaches to gain the desired heat transfer rate is by manipulating the nanoparticles solid volume fractions.

Figure 3 demonstrates the variations of $\mathrm{Re}_{x}^{-1 / 2} N u_{x}$ towards $\lambda$ with selected values of Marangoni parameter $M a$. As $M a$ increases, the rate of heat transfer declines for the shrinking sheet, slightly increases for the stretching sheet and unique for flat surface. The value of $\operatorname{Re}_{x}^{-1 / 2} N u_{x}$ for stretching case is greater as compared to the shrinking case. Figures 4 and 5 illustrate the velocity and temperature profiles with the increment of $M a$. The velocity of first (physical) solution diminishes while second solution shows opposite results. Meanwhile, the temperature of both solutions inclines, and this result is in conjunction with the result in Figure 3.

Figures 6 and 7 exhibit the impact of suction parameter $S$ on hybrid nanofluid velocity and temperature. As suction enhances, the velocity increases for first solution and decreases for second solution while $S$ tends to deteriorate the temperature for both solutions. This result is parallel with results published by Bakar et al. (2018). The fluid suction may assist the heated fluid towards the surface, boost the thermal boundary layer thickness and subsequently, reduce the fluid temperature. Besides, an upsurge of the suction parameter also can reduce the momentum boundary layer thickness and generate the flow near to the surface. The thermal efficiency of $\mathrm{Cu}-\mathrm{Al}_{2} \mathrm{O}_{3} /$ water hybrid nanofluid is dominant for the larger values of the shrinking sheet as manifested in Figure 2, hence, for this analysis, as manifested in Figures 8 and $9, \lambda+-2$ is chosen to investigate the change of velocity and temperature as $\phi_{2}$ increased. The enhancement of $\phi_{2}$ seems to boost both profiles as depicted in Figures 8 and 9. The increment of nanoparticles volume fraction may physically dissipate more energy (heat) which simultaneously, intensifies the temperature.

The purpose of the stability analysis is to prove the reliability of the first solution as the real solution. The linearized eigenvalue model in (21)-(23) is solved by using MATLAB code bvp4c to examine the possible eigenvalues where $\gamma_{1}$ serves as a determinant of the stability solution. The sign value of $\gamma_{1}$ is essential to determine the flow characteristics such that positive $\gamma_{1}$ will indicate the stability of the flow. Negative $\gamma_{1}$ means that the initial growth of disturbances arise which reflects that the flow is unstable. The smallest eigenvalue, $\gamma_{1}$ are tabulated in Table 4 , and it shows that the first and second solutions have positive and negative eigenvalues, accordingly. It can also be seen from Figure 10 that $\gamma_{1}$ of both solutions approach to 0 as $\gamma_{1} \rightarrow \gamma_{3}$

\section{CONCLUSION}

The present study scrutinises the heat transfers and flow characteristics of thermal Marangoni flow towards a permeable stretching/shrinking sheet. Hybrid nanofluid with a suitable combination of nanoparticles is known to have better heat transfer performance as compared to the traditional nanofluid. The combination of $\mathrm{Al}_{2} \mathrm{O}_{3}\left(\phi_{1}\right)$ and $\mathrm{Cu}\left(\phi_{2}\right)$ nanoparticles with water as the working fluid was used in the study. The similarity transformation was utilised to convert the governing model in PDEs into a set of ODEs and then numerically solved by using Matlab function bvp4c. The conclusions of present work are as follows:

The rate of heat transfer increases as $\phi_{2}$ increases for larger values of shrinking parameter and opposite result is obtained for all values of stretching parameter. As the Marangoni parameter $\mathrm{Ma}$ enhances, the rate of heat transfer decreases for the shrinking sheet $\lambda \rightarrow-\lambda$, slightly increases for the stretching sheet $\lambda \rightarrow+\lambda$ and unique for flat surface $(\lambda=0)$. Velocity profile of first solution inclines with the increment of suction parameter $S$, and $\phi_{2}$ while declines as $M a$ increases. Meanwhile, the velocity profile of second solution shows opposite changes. Temperature profile for both solutions escalates with the addition of $M a$ and $\phi_{2}$ while lessens with the enhancement of $S$. The execution of stability analysis affirms that the first solution is physically acceptable, and second solution is not a physical solution.

\section{ACKNOWLEDGEMENTS}

The authors would like to recognize Universiti Putra Malaysia through the Putra grant - 9570600. The work by Ioan Pop has been supported from the grant PN-III-P4-IDPCE-2016-0036, UEFISCDI, Romania. The main author also would like to acknowledge the Ministry of Education (Malaysia) and Universiti Teknikal Malaysia Melaka for the financial support through UTEM-SLAB scholarship. We also appreciate the worthwhile feedbacks and suggestions by the competent reviewers.

\section{REFERENCES}

Ahmadi, M. \& Willing, G. 2018. Heat transfer measurement in water based nanofluids. International Journal of Heat and Mass Transfer 118: 40-47.

Ahmadi, M.H., Mirlohi, A., Alhuyi Nazari, M. \& Ghasempour, R. 2018. A review of thermal conductivity of various nanofluids. Journal of Molecular Liquids 265: 181-188.

Akbarzadeh, M., Rashidi, S., Karimi, N. \& Ellahi, R. 2018. Convection of heat and thermodynamic irreversibilities in two-phase, turbulent nanofluid flows in soalr heaters by corrugated absorber plates. Advanced Powder Technology 29: 2243-2254.

Akilu, S., Sharma, K.V., Baheta, A.T. \& Mamat, R. 2016. A review of thermophysical properties of water based composite nanofluids. Renewable and Sustainable Energy Reviews 66: 654-678.

Alamri, S.Z., Ellahi, R., Shehzad, N. \& Zeeshan, A. 2019. Convective radiative plane Poiseuille flow of nanofluid through porous medium with slip: An application of Stefan blowing. Journal of Molecular Liquids 273: 292-304. 
Amirsom, N.A., Uddin, M.J., Basir, M.F.M., Ismail, A.I.M., Bég, O.A. \& Kadir, A. 2019. Three-dimensional bioconvection nanofluid flow from a bi-axial stretching sheet with anisotropic slip. Sains Malaysiana 48(5): 1137-1149.

Arifin, N.M., Nazar, R. \& Pop, I. 2013. Similarity solution of Marangoni convection boundary layer flow over a flat surface in a nanofluid. Journal of Applied Mathematics 2013: Article ID. 634746.

Arifin, N.M., Nazar, R. \& Pop, I. 2011. Non-isobaric Marangoni boundary layer flow for $\mathrm{Cu}, \mathrm{Al} 2 \mathrm{O} 3$ and $\mathrm{TiO} 2$ nanoparticles in a water-based fluid. Meccanica 46(4): 833-843.

Aziz, R.C., Hashim, I. \& Abbasbandy, S. 2018. Flow and heat transfer in a nanofluid thin film over an unsteady stretching sheet. Sains Malaysiana 47(7): 1599-605.

Babu, J.A.R., Kumar, K.K. \& Rao, S.S. 2017. State-of-art review on hybrid nanofluids. Renewable and Sustainable Energy Reviews 77: 551-565.

Bahiraei, M. \& Mazaheri, N. 2018. Application of a novel hybrid nanofluid containing graphene-platinum nanoparticles in a chaotic twisted geometry for utilization in miniature devices: Thermal and energy efficiency considerations. International Journal of Mechanical Science 138: $337-$ 349.

Bachmann, M., Avilov, V., Gumenyuk, A. \& Rethmeier, M. 2016. Numerical assessment and experimental verification of the influence of the Hartmann effect in laser beam welding processes by steady magnetic fields. International Journal of Thermal Science 101: 24-34.

Bournival, G., Ata, S. \& Jameson, G.J. 2017. Bubble and froth stabilizing agents in froth flotation. Mineral Processing and Extractive Metallurgy Review 38(6): 366-387.

Bakar, N.A., Bachok, N. \& Arifin, N.M. 2018. Stability analysis on the flow and heat transfer of nanofluid past a stretching/ shrinking cylinder with suction effect. Results in Physics 9: $1335-1344$.

Cui, C.Y., Li, X.D., Fang, C., Zhang, W.L., Ruan, Z.W., Cui, X.G., Lu, J.Z., Xia, C.D. \& Lu, Y.F. 2018. Effects of Marangoni convection on the embedding dynamic behavior of $\mathrm{SiC}$ nano-particles into the $\mathrm{Al}$ molten pool during laser micro-melting. Materials \& Design 143: 256-267.

Devi, S.S.U. \& Devi, S.P.A. 2017. Heat transfer enhancement of $\mathrm{Cu}-\mathrm{Al}_{2} \mathrm{O}_{3} /$ water hybrid nanofluid flow over a stretching sheet. Journal of the Nigerian Mathematical Society 36(2): 419-433.

Devi, S.P.A. \& Devi, S.S.U. 2016a. Numerical investigation of hydromagnetic hybrid $\mathrm{Cu}-\mathrm{Al}_{2} \mathrm{O}_{3}$ /water nanofluid flow over a permeable stretching sheet with suction. International Journal of Nonlinear Sciences and Numerical Simulation 17(5): 249-257.

Devi, S.S.U. \& Devi, S.P.A. 2016b. Numerical investigation of three-dimensional hybrid $\mathrm{Cu}-\mathrm{Al} 2 \mathrm{O} 3 /$ water nanofluid flow over a stretching sheet with effecting Lorentz force subject to Newtonian heating. Canadian Journal of Physics 94(5): 490-496.

Dzulkifli, N., Bachok, N., Yacob, N., Arifin, N.M. \& Rosali, H. 2018. Unsteady stagnation-point flow and heat transfer over a permeable exponential stretching/shrinking sheet in nanofluid with slip velocity effect: A stability analysis. Applied Sciences 8(11): 2172.

Ellahi, R., Alamri, S.Z., Basit, A. \& Majeed, A. 2018. Effects of MHD and slip on heat transfer and boundary layer flow over a moving plate based on specific entropy generation. Journal of Taibah University for Science 12(4): 476-482.

Ellahi, R., Zeeshan, A. \& Hassan, M. 2016. Particle shape effects on Marangoni convection boundary layer flow of a nanofluid. International Journal of Numerical Methods for Heat \& Fluid Flow 26(7): 2160-2174.

Ellahi, R. 2013. The effects of MHD and temperature dependent viscosity on the flow of non-Newtonian nanofluid in a pipe: Analytical solutions. Applied Mathematical Modelling 37(3): 1451-1457.

Fang, T., Yao, S., Zhang, J. \& Aziz, A. 2010. Viscous flow over a shrinking sheet with a second order slip flow model. Communications in Nonlinear Science and Numerical Simulation 15(7): 1831-1842.

Ghadikolaei, S.S., Yassari, M., Sadeghi, H., Hosseinzadeh, K. \& Ganji, D.D. 2017. Investigation on thermophysical properties of $\mathrm{TiO}_{2}-\mathrm{Cu} / \mathrm{H}_{2} \mathrm{O}$ hybrid nanofluid transport dependent on shape factor in MHD stagnation point flow. Powder Technology 322: 428-438.

Ghalambaz, M., Sheremet, M.A., Mehryan, S.A., Kashkooli, F.M. \& Pop, I. 2019. Local thermal non-equilibrium analysis of conjugate free convection within a porous enclosure occupied with $\mathrm{Ag}-\mathrm{MgO}$ hybrid nanofluid. Journal of Thermal Analysis and Calorimetry 135(2): 1381-1398.

Gupta, M., Singh, V., Kumar, S., Kumar, S., Dilbaghi, N. \& Said, Z. 2018. Up to date review on the synthesis and thermophysical properties of hybrid nanofluids. Journal of Cleaner Production 190: 169-192.

Hamid, R.A. \& Arifin, N.M. 2014. The effect of wall suction/ injection on MHD Marangoni convection boundary layer flow in nanofluid. AIP Conference Proceedings 1605(1): 386-391.

Hamid, R.A. \& Nazar, R. 2016. Stability analysis of MHD thermosolutal Marangoni convection boundary layer flow. AIP Conference Proceedings 1750(1): 030022

Harris, S.D., Ingham, D.B. \& Pop, I. 2009. Mixed convection boundary-layer flow near the stagnation point on a vertical surface in a porous medium: Brinkman model with slip. Transport in Porous Media 77(2): 267-285.

Hassan, M., Marin, M., Alsharif, A. \& Ellahi, R. 2018a. Convection heat transfer flow of nanofluid in a porous medium over wavy surface. Physics Letters A 382: 27492753

Hassan, M., Marin, M., Ellahi, R. \& Alamri, S.Z. 2018b. Exploration of convective heat transfer and flow characteristics synthesis by $\mathrm{Cu}-\mathrm{Ag} /$ water hybridnanofluids. Heat Transfer Research 49(18): 1837-1848.

Hassan, M., Ellahi, R., Bhatti, M.M. \& Zeeshan, A. 2019. A comparative study of magnetic and non-magnetic particles in nanofluid propagating over a wedge. Canadian Journal of Physics 97(3): 277-285.

Hayat, T. \& Nadeem, S. 2017. Heat transfer enhancement with $\mathrm{Ag}-\mathrm{CuO} /$ water hybrid nanofluid. Results in Physics 7: 2317-2324.

Hayat, T., Nadeem, S. \& Khan, A.U. 2018. Rotating flow of Ag$\mathrm{CuO} / \mathrm{H}_{2} \mathrm{O}$ hybrid nanofluid with radiation and partial slip boundary effects. European Physical Journal E 41(6): 75.

Hayat, T., Khan, M.I., Farooq, M., Alsaedi, A. \& Yasmeen, T. 2017. Impact of Marangoni convection in the flow of carbon-water nanofluid with thermal radiation. International Journal of Heat and Mass Transfer 106: 810-815.

Huminic, G. \& Huminic, A. 2018. Hybrid nanofluids for heat transfer applications - A state-of-the-art review. International Journal of Heat and Mass Transfer 125: 82103.

Huminic, G. \& Huminic, A. 2019. The influence of hybrid nanofluids on the performances of elliptical tube: Recent 
research and numerical study. International Journal of Heat and Mass Transfer 129: 132-143.

Jana, S., Salehi-Khojin, A. \& Zhong, W.H. 2019. Enhancement of fluid thermal conductivity by the addition of single and hybrid nano-additives. Thermochimica Acta 462(1-2): 45-55.

Jamaludin, A., Nazar, R. \& Pop, I. 2018. Ingham problem for mixed convection flow of a nanofluid over a moving vertical plate with suction and injection effects. Sains Malaysiana 47(9): 2213-2221.

Kamal, F., Zaimi, K., Ishak, A. \& Pop, I. 2019. Stability analysis of mhd stagnation-point flow towards a permeable stretching/shrinking sheet in a nanofluid with chemical reactions effect. Sains Malaysiana 48(1): 243-250.

Kamyar, A., Saidur, R. \& Hasanuzzaman, M. 2012. Application of computational fluid dynamics (CFD) for nanofluids. International Journal of Heat and Mass Transfer 55(1516): 4104-4115.

Khanafer, K., Vafai, K. \& Lightstone, M. 2003. Buoyancy driven heat transfer enhancement in a two-dimensional enclosure utilizing nanofluids. International Journal of Heat and Mass Transfer 46(19): 3639-3653.

Khashi'ie, N.S., Arifin, N.M., Hafidzuddin, E.H., Wahi, N. \& Ilias, M.R. 2019. Magnetohydrodynamics (MHD) flow and heat transfer of a doubly stratified nanofluid using Cattaneo-Christov model. Universal Journal of Mechanical Engineering 7(4): 206-214.

Kidess, A., Kenjereš, S., Righolt, B.W. \& Kleijn, C.R. 2016. Marangoni driven turbulence in high energy surface melting processes. International Journal of Thermal Science 104: 412-422.

Lin, Y. \& Zheng, L. 2015. Marangoni boundary layer flow and heat transfer of copper-water nanofluid over a porous medium disk. AIP Advances 10: 107225.

Lin, Y., Li, B., Zheng, L. \& Chen, G. 2016. Particle shape and radiation effects on Marangoni boundary layer flow and heat transfer of copper-water nanofluid driven by an exponential temperature. Powder Technology 301: 379-386.

Mahat, R., Rawi, N.A., Kasim, A.R. \& Shafie, S. 2018. Mixed convection flow of viscoelastic nanofluid past a horizontal circular cylinder with viscous dissipation. Sains Malaysiana 47(7): 1617-23.

Mat, N.A., Arifin, N.M., Nazar, R., Ismail, F. \& Pop, I. 2017. Radiation effects on Marangoni convection boundary layer over a permeable surface. Meccanica 48(1): 83-89.

Merkin, J.H. 1986. On dual solutions occurring in mixed convection in a porous medium. Journal of Engineering Mathematics 20(2): 171-179.

Miklavčič, M. \& Wang, C.Y. 2006. Viscous flow due to a shrinking sheet. Quarterly of Applied Mathematics 64(2): 283-290.

Minakuchi, H., Okano, Y. \& Dost, S. 2017. Effect of thermosolutal Marangoni convection on the azimuthal wave number in a liquid bridge. Journal of Crystal Growth 468: 502-505.

Mohamed, M.K., Noar, N.A., Salleh, M.Z. \& Ishak, A. 2016. Free convection boundary layer flow on a horizontal circular cylinder in a nanofluid with viscous dissipation. Sains Malaysiana 45(2): 289-296.

Nadeem, S., Abbas, N. \& Khan, A.U. 2017. Characteristics of three dimensional stagnation point flow of hybrid nanofluid past a circular cylinder. Results in Physics 8: 829-835.

Naganthran, K., Nazar, R. \& Pop, I. 2018. Effects of thermal radiation on mixed convection flow over a permeable vertical shrinking flat plate in an Oldroyd-B fluid. Sains Malaysiana 47(5): 1069-1076.
Oztop, H.F. \& Abu-Nada, E. 2008. Numerical study of natural convection in partially heated rectangular enclosures filled with nanofluids. International Journal of Heat and Fluid Flow 29(5): 1326-1336.

Rashidi, S., Akar, S., Bovand, M. \& Ellahi, R. 2018. Volume of fluid model to simulate the nanofluid flow and entropy generation in a single slope solar still. Renewable Energy 115: 400-410.

Raza, M.Q., Kumar, N. \& Raj, R. 2018. Surfactants for bubble removal against buoyancy. Scientific Reports 6: 19113.

Rostami, M.N., Dinarvand, S. \& Pop, I. 2018. Dual solutions for mixed convective stagnation-point flow of an aqueous silica-alumina hybrid nanofluid. Chinese Journal of Physics 56(5): 2465-2478.

Roşca, A.V. \& Pop, I. 2013. Flow and heat transfer over a vertical permeable stretching/shrinking sheet with a second order slip. International Journal of Heat and Mass Transfer 60: 355-364.

Sarkar, J., Ghosh, P. \& Adil, A. 2015. A review on hybrid nanofluids: Recent research, development and applications. Renewable and Sustainable Energy Reviews 43: 164-177.

Sastry, D.R., Murti, A.S. \& Kantha, T.P. 2013. The effect of heat transfer on MHD Marangoni boundary layer flow past a flat plate in nanofluid. International Journal of Engineering Mathematics 2013: Article ID. 581507.

Shampine, L.F., Gladwell, I., Shampine, L. \& Thompson, S. 2003. Solving ODES with Matlab. Cambridge: Cambridge University Press.

Sheikholeslami, M. \& Ganji, G. 2017. Influence of magnetic field on CuO-H2O nanofluid flow considering Marangoni boundary layer. International Journal of Hydrogen Energy 42(5): 2748-2755.

Sheikholeslami, M. \& Chamkha, A.J. 2017. Influence of Lorentz forces on nanofluid forced convection considering Marangoni convection. Journal of Molecular Liquids 225: 750-757.

Sheikholeslami, M., Ellahi, R., Shafee, A. \& Li, Z. 2019. Numerical investigation for second law analysis of ferrorfluid inside a porous semi annulus: An application of entropy generation and exergy loss. International Journal of Numerical Methods for Heat and Fluid Flow 29(3): 1079-1102.

Sidik, N.A.C., Adamu, I.M., Jamil, M.M., Kefayati, G.H.R., Mamat, R. \& Najafi, G. 2016. Recent progress on hybrid nanofluids in heat transfer applications: A comprehensive review. International Communications in Heat and Mass Transfer 78: 68-79.

Sohail, A., Fatima, M., Ellahi, R. \& Akram, K.B. 2019. A videographic assessment of ferrofluid during magnetic drug targeting: An application of artifical intelligence in nanomedicine. Journal of Molecular Liquids 285: 47-57.

Soid, S.K., Ishak, A. \& Pop, I. 2018. MHD stagnation-point flow over a stretching/shrinking sheet in a micropolar fluid with a slip boundary. Sains Malaysiana 47(11): 2907-2916.

Soltani, O. \& Akbari, M. 2016. Effects of temperature and particles concentration on the dynamic viscosity of MgOMWCNT/ethylene glycol hybrid nanofluid: experimental study. Physica E: Low-dimensional Systems and Nanostructures 84: 564-570.

Sundar, L.S., Sharma, K.V., Singh, M.K. \& Sousa, A.C.M. 2017. Hybrid nanofluids preparation, thermal properties, heat transfer and friction factor - A review. Renewable and Sustainable Energy Reviews 68: 185-198.

Timofeev, V.V., Kalaev, V.V. \& Ivanov, V.G. 2015. 3D melt convection in sapphire crystal growth: Evaluation of 
physical properties. International Journal of Heat and Mass Transfer 87: 42-48.

Vafaei, M., Afrand, M., Sina, N., Kalbasi, R., Sourani, F. \& Teimouri, H. 2017. Evaluation of thermal conductivity of MgO-MWCNTs/EG hybrid nanofluids based on experimental data by selecting optimal artificial neural networks. Physica E: Low-dimensional Systems and Nanostructures 85: 90-96.

Waini, I., Ishak, A. \& Pop, I. 2019. Hybrid nanofluid flow and heat transfer over a nonlinear permeable stretching/ shrinking surface. International Journal of Numercial Methods for Heat and Fluid Flow 29(9): 3110-3127.

Weidman, P.D., Kubitschek, D.G. \& Davis, A.M.J. 2006. The effect of transpiration on self-similar boundary layer flow over moving surfaces. International Journal of Engineering Science 44(11-12): 730-737.

Yahaya, R., Arifin, N.M. \& Mohamed Isa, S. 2018. Stability analysis on magnetohydrodynamic flow of casson fluid over a shrinking sheet with homogeneous-heterogeneous reactions. Entropy 20(9): 652.

Yousif, M.A., Ismael, H.F., Abbas, T. \& Ellahi, R. 2019. Numerical study of momentum and heat transfer of MHD Carreau nanofluid over exponentially stretched plate with internal heat source/sink and radiation. Heat Transfer Research 50(7): 649-658.

Zaimi, K., Ishak, A. \& Pop, I. 2017. Unsteady flow of a nanofluid past a permeable shrinking cylinder using Buongiorno's model. Sains Malaysiana 46(9): 1667-1674.

Najiyah Safwa Khashi'ie \& Norihan Md Arifin* Institute for Mathematical Research

Universiti Putra Malaysia

43400 UPM Serdang

Selangor Darul Ehsan

Malaysia
Najiyah Safwa Khashi'ie

Fakulti Teknologi Kejuruteraan Mekanikal dan Pembuatan

Universiti Teknikal Malaysia Melaka, Hang Tuah Jaya

76100 Durian Tunggal, Melaka

Malaysia

Norihan Md Arifin* \& Nadihah Wahi

Department of Mathematics, Faculty of Science

Universiti Putra Malaysia

43400 UPM Serdang, Selangor Darul Ehsan

Malaysia

Ioan Pop

Department of Mathematics

Babeş-Bolyai University

400084 Cluj-Napoca

Romania

Roslinda Nazar

Pusat Pengajian Sains Matematik

Fakulti Sains dan Teknologi

Universiti Kebangsaan Malaysia

43600 UKM Bangi, Selangor Darul Ehsan

Malaysia

Ezad Hafidz Hafidzuddin

Centre of Foundation Studies for Agricultural Science Universiti Putra Malaysia

43400 UPM Serdang, Selangor Darul Ehsan

Malaysia

*Corresponding author; email: norihana@upm.edu.my

Received: 17 June 2019

Accepted: 18 October 2019 